\title{
Employee Retention Factors in Nepali Insurance companies
}

\author{
Pitambar Ghimire, MPhil \\ Faculty, K\&K College \\ pitambar2072@gmail.com
}

\begin{abstract}
Employee retention is complex phenomenon that requires strategic orientation towards retention factors. The objective of the study is to find out factors influencing employee retention and examine them with retention intention. The 125 respondent (sample) with different categories are taken from various insurance companies. The stratified sampling method is used to make the sample representation and convenient sampling has been used to select the sample unit. Descriptive statistics, correlation analysis, hypothesis testing are carried out to examine the retention intention. The research paper concludes that the employee retention is complex management job and it needs high level commitment. All retention factors have positive impact on retention intention.
\end{abstract}

Keywords; Retention, Benefits, Opportunities, Career

\section{Introduction}

Especially, keyortalentemployees arevaluableasset of theorganization. Theretention of such employees' is one of the significant issues of contemporary context. Managing employee retention and keeping turnover rate below target and industry norms is one of the most challenging issues facing organizations (Philips and Connel, 2003). Organization needs favorable HR practices and retention strategies, which let the key employees adhere to an organization and reduce rate of employee turnover. Retaining function comprise the activities of rewarding employees for performing their job effectively, ensuring harmonious working relation between employees and managers and maintaining a safe and healthy work environment. Fair treatment of employees, open communication, face-to-face resolution of conflict, promotion of teamwork, respect for the dignity of each individual and pay inc reases based on merit are essential to retain employees (Cascio, 2006).

Employee retention is about finding the best of employee for the job and finding ways of keeping these employees within the department. It involves a range of ideas and 
human resource practices that should all be seen as interlinked such as giving focus both on attracting employees to join the organization through focusing on recruitment strategies and keeping those who are already employed, especially those posses scarce skills that are difficult to get them from labor market and are more crucial to the organization (Samuel and Chipunja, 2009).

Human resource management (HRM) is an important area in the field of management. It is the set of programs, functions and activities designed and carried out in order to maximize both employees as well as organizational effectiveness (Aswathappa, 2005). This is the process which consists of the acquisition, development, motivation and maintenance of human resource (DeCenzo and Robbins, 2005). It also focuses on engender commitment among employees by winning their hearts (Jyoth and Venkatesh, 2006). HRM contributes to key employee retention for longer period of time in an organization. It is directly related to creating a satisfactory work environment for employees and thus, in turn, to have good retention (Griffeth, et. al, 1995). The responsibility of recruiting and selecting the right person for the organization is human resource (HR) department. This department ensures right person at right place at right time. It also provides training and development to the employees for their efficient performance (Khadka, 2009). Retention of key employees is an important aspect of HRM. Thus, "recruiting and selecting the people to meet the organization's human resource needs is only first half the battle in the war for talent; the second half is keeping them (Schuler \&Jackson, 2006). Qualified, motivated and experienced employees are essential for survival, growth and development of an organization.

Employee retention is the ability to hold onto those employees you want to keep, for longer than your competitors (Johnson, 2000). Retention of skilled employees has been a serious concern to managers in the face of ever increasing high rate of employee turnover (Samuel and Chipunja, 2009). Studies show that high turnover rates in the financial institutions are not country specific and this is a worldwide epidemic. Employees are an institution's most important resource, whether this institution is privately or publicly owned. The reason for it is due to the fact that employees are there to carry out the functions of the institution, so that the institution can either; make a profit, in the case of private companies or deliver basic services to citizens or inhabitants of a particular territory, in the case of government institutions. Despite which sector of society is involved, the human resources of that sector remain a priority, in the sense that their knowledge is invaluable to the institution.

The insurance sector of Nepal is facing manpower crunch due to lack of attention given to human resources, because of these reasons, the need of efficient insurance employees has doubled and is expected to grow furthermore incoming years, both the retention and hiring of staff has turned out to be a major issue, as a result Insurance are making heavy investments in screening the right kind of staff. The trend of poaching workers among Insurance and lack of succession planning at managing senior level officials are other problems due to which Insurance are bound to face when it comes to 
HRM. Most organizations today continue to struggle with retain hardly because they are only relying on salary increases and bonuses to prevent turnover (Gumbus and Johnson, 2003). Managing core employees effectively means identifying their needs. Employees bring their needs, aspirations, and hopes to their jobs and working environment where their abilities can be utilized and their basic needs can be satisfied.

High employee turnover is a problem for entrepreneurs around the world. The problem appears to be even more burdensome to Nepali entrepreneurs as it is incredibly difficult to find talent in the market; retaining them is even more of a challenge. Rather than losing employees to a competitor, there is a higher likelihood of losing them to the higher paying non-profit sector or the employee going abroad to pursue further education. For startups, retaining employees can pose even greater problems as Nepali culture promotes 'safety' when it comes to careers. As a result, young graduates are more comfortable finding jobs in larger corporations like banks and business house.

It is because when an employee leaves an organization then it incurs a huge loss and an unbalanced situation to the internal environment of the organization. So, based on the above discussion, the study aims to identify the factors which influence the retention of employees working in the insurance sector of Nepal.

\section{Objectives}

To identify the factors influencing the employees retention in Nepali insurance companies. To examine the impact of salary and benefits, career opportunities, work life balance on employee retention.

\section{Hypotheses}

H7: There is significant relation between salary and benefits and employee retention.

H2: There is significant relation between career opportunities and employee retention intention.

H3: There is significant relation between work life balance and employee retention intention.

\section{Review of Literature}

Determinants of Employee Retention

This section presents the major factors affecting on retention intention of employees. Based on the review of available literatures, the following factors have been identified.

\section{Salary and Benefits}

The total amount of financial and non-financial rewards and benefits provided by an employer to an employee in contrast to the work performed as required and as part of an employment relationship is termed as compensation (Heneman and Schwab, 1985). It is true that compensation plays an important role in complex and global organizations. However, there is no such thing as a perfect compensation system and the need for 
adjustment will be done trying to retain it but there is no permanent system and the need for adjustment will be done according to the changes in business environment and local national culture. Apparently, it seems natural that there is a positive relationship between annual income and overall organizational commitment. Some findings have conflicting opinions, perhaps due to the variation of cultures and economics systems/conditions of the places in which researches were conducted but most of the findings favor the opinion that salary and benefits has directly or were conducted but most of the findings favor the opinion that salary and benefits has directly or indirectly positive relationship with employees' commitment. Essential, corporate culture may affect the compensation practices as it is embedded in the national culture.

\section{Career Opportunities}

The career progression is an arrangement which is intended and designed to cater the needs of employees related to their career as well as the organizations' expectation from its human capital so that both can achieve maximum level of satisfactions. The enhancement in awareness makes it obvious that the power of people can only take an organization to the top level. It is the human resource department which had huge responsibility on its shoulders to formulate such plans and strategies that instigate that employees loyalty toward the goals and objectives of the firm so that employees get inspired and work hard positively in the favor of the company and keep the company in the list of top companies (Graddick, 1998). The company which needs strong and positive relations with its workers must have to do much in the favor of the workers and for their betterments. The companies need competent workers which lead them to the path of success for the long term on the other hand the workers need good opportunities for bright and glowing career (Prince, 2005). In order to improve retention, a company should align career development policies with the needs of employees (Mak and Sockel, 2001., Hytter, 2007). Career Planning process, developed a new approach to retain and develop talent. Through an associate review that looks forward rather than backward, Career Planning helps the associate understand all the opportunities available within the firm. Factors affecting their retention and how the management should provide incentives to them through offering them a career ladder through which they might progress.

\section{Work-Life Balance}

Employees are being rewarded with significance and are given magnitude because of a balance work-life plan. Some of the employees are loyal with the company and they don't think of switching the jobs they are engaged in. They are mostly afraid of the schedule of their work because at times the work effect their personal and social life but they try to balance but those employees who are in the hunt of a new job show different attitude (Dubie, 2000). Many researchers are working on the contact between the work and the family issues that if both of them are affected by each other or not some of these issues are the easy working hours, taking care of the children's, parental leaves information regarding child care and leaves with commitment of the organization. Research has notified that the organizations show high level of loyalty if the employees have to face work-life plans. Deery (2008) and Swanepoel et., al. (2000) recommended 
actions that can be adopted by organization in order to retain good staff, as well as assist in balancing work and family life, as shown below:

- Allowing flexible work arrangements such as job sharing and working from home

- Determining correct staffing levels so that staff is not overloaded

- Allowing adequate breaks during the working day

- Having provision for various types of leave such as career leave and time-out sabbatical types of leave

- Staff functions that involve families

- Providing child and elder (parent) care facilities

- Involving spouses and children in certain recreational, fitness and other social activities and facilities of the organizations

Work-life policies correlate positively with employee retention which means favorable work-life policies of the organization help to increase employee retention (Shoaibet, et.al., 2009). The higher levels of satisfaction, supervisor support, fringe benefits, teamwork, working environment, and training were positively associated with the higher level of organizational loyalty. The factors of satisfaction, supervisor support, teamwork, and working environment play crucial roles and significantly affect employee's loyalty. Based on the results of the path analysis, this study argued that in order to achieve high employee loyalty, companies in banking industry should achieve high level of employee job satisfaction, enhance supervisor support and teamwork among employees, and provide good working environment In addition, this study also elicited employee s views on the different factors contributing to their loyalty toward their current banks (Khuong and Tien, 2013). Mohamed, Ngui and Mulil (2017) found that the working environment influences employee retention as was supported by majority of respondents who indicated that the bank believes that good working conditions plays a significant role in employee's intention to stay, presence of proper communication culture that has attributed to employee retention at the bank and presence of competent leadership led to the improvement in the employee retention.

\section{Research Methodology}

The descriptive and analytical research design has been used to test the research hypothesis. Multiple regression analysis has used to examine the impact of retention factors on retention intention. Descriptive research includes surveys and fact-finding enquiries. Descriptive research is used to describe the variables used in the study in term of what has happened or what is happening. In analytical research, on the other hand, the researcher has to use facts or information already available, and analyze these to make a critical evaluation of the material reflecting the relation and impact of variables used in the study. It attempts to cover the perceptual and attitudinal aspect of employees towards retention intention. The study has focused on determining the determinants of employee retention.

The primary data is collected through questionnaire filled up by the employees. The questionnaire is simple and understandable to all level of employees, which has focused 
on the employee retention intention. The relevant data obtained from sample has recorded in spreadsheet format using Microsoft excel and the SPSS. Excel and SPSS tools are used to process and extract the result from the available information.

There are 39 insurance companies in Nepal. Among them 18 are life insurance 20 are non life insurance and 1 is Reinsurance Company. Among them, 4 insurance companies (Nepal Life Insurance Company, Prime Life Insurance Company, Guras Life Insurance Company, and Asian Life Insurance Company) have been taken based for the study. For the research purpose the population of the study constitutes both officer and assistant level employees working in Kathmandu valley. It constitutes the employees working in both corporate and branch offices of insurance company. There are 125 respondents Among them 30 from Nepal life insurance company limited, 35 from prime life insurance company, 25 from Guras life insurance company limited and 25 from Asian life insurance company limited. The independent sample t-test is carried out to test the priori hypothesis on impact of age, gender and level of education, job position years of involvement, years of experience on retention intention.

\section{Results}

Descriptive Analysis

Since the Likert items are design with increasing i.e. 5 is assigned for strongly agree and 1 is sdesigned for strongly disagree. In such situation, greater mean values indicate the positive response towards retention intention of employee. The mean value of retention intention is 2.9759 indicates that employees are delivering their opinion in the favor of retention intention.

Similarly, The mean score of career opportunity and work life balance are more than 3 (3.1814 and 3.2270) indicating that employees are reflecting positive opinions towards organizational efforts and facilities regarding career opportunities and work life balance where as the mean score of salary and benefits is less than 3 (2.6241) which indicates employees are not being satisfied from salary and benefits provided by the organization and they have no clear intention for staying in the organization.

Association between Retention Factors and Retention Intention of Employees

This section analyses the relationship between the retention factors and retention intention of employees of selected insurance company. Correlation coefficient between dependent and independent variables reflect the relationship and association. Table summarizes the association between the retention variables and retention intention. 
Table 1

Association between Retention Factor and Retention Intention

\begin{tabular}{|c|c|c|c|c|}
\hline Variables & $\begin{array}{c}\text { Retention } \\
\text { Intention }\end{array}$ & $\begin{array}{c}\text { Salary \& } \\
\text { Benefits }\end{array}$ & Career opportunity & $\begin{array}{c}\text { Work life } \\
\text { Balance }\end{array}$ \\
\hline Retention Intentions & 1 & $0.864 * *$ & $0.788^{* *}$ & $0.667 * *$ \\
\hline
\end{tabular}

* significant at 0.05level of significance

$* *$ Significant at 0.01 level of significance

Salary and benefits and retention intension was examined by calculating the correlation coefficient. The correlation coefficient has been found 0.864 , which is significant at 1 percent level of significance. It shows that there is positive correlation between salary and benefits and retention intension of employees of selected insurance companies. Work Life balance is an additional dependent variable under the scope of our study. Four different questions were included to get the opinion of respondents on work life balance related issues. Calculation shows that there is positive correlation between work life policy and the retention intention of employees. Value of correlation coefficient is 0.667 which is significant at 1 percent level of significance. Response on five questions related to career opportunity of employees included in questionnaire shows that there is positive correlation in between retention intention and career opportunity. The correlation coefficient is significant at 1 percent level of significance. Value of correlation coefficient between retention intention and career opportunity has been found 0.788 .

\section{Correlation Coefficient Helps to Test Hypothesis}

In the result of Pearson correlation test, a significant correlation has found between salary and benefits and retention intention of employee at 1 percent level of significance $(p<0.01)$. The result has provided sufficient evidence for that there is significant relationship between salary and benefits and retention intention. In the result of Pearson correlation test, a significant correlation has found between career opportunity and retention intention of employee at 1 percent level of significance $(p<0.01)$. The result has provided sufficient evidence for that there is significant relationship between career opportunity and retention intention. In the result of Pearson correlation test, a significant correlation has found between work life balance and retention intention of employee at 1 percent level of significance $(p<0.01)$. The result has provided sufficient evidence for that there is significant relationship between work life balance and retention intention. One way ANOVA suggests that significant different does not exist in the opinion of employees towards retention intention across age group, educational level, years of involvement and years of experience of employees. Retention intention is not affected by age group, educational level, years of involvement and years of experience of employees.

\section{Impact of Retention Factors on Retention Intention}

This section investigates the impact of retention factor on retention intention. In this connection, multiple regressions has been used keeping retention intention as dependent and retention factors (salary and benefits, career opportunities, work life balance) as independent variables. Table 2 summarizes the result of regression analysis. 
Table 2

Result of Multiple Regression Analysis

\begin{tabular}{lcccc}
\multicolumn{1}{c}{ Items } & Beta & Std. error & t-value & p-value \\
\hline Constant & 21.466 & 2.734 & 7.851 & 0.000 \\
Salary and benefits & 0.564 & 0.053 & 10.602 & 0.000 \\
Career opportunities & 0.245 & 0.037 & 6.561 & 0.000 \\
work life balance & 0.145 & 0.026 & 3.043 & 0.02 \\
R-square=0.603, DW=1.972, & & & & \\
$\mathrm{F}=75.073$ and $\mathrm{p}$-value<0.05 & & & & \\
\hline
\end{tabular}

The concrete result of multiple regression shows that the regression model retention factors and retention intention is significant $F=75.073, p<0.05$. Hence, it concludes that there is sufficient evidence, at the $5 \%$ level of significance, that there is a linear relationship between retention intention and retention factors. Even the value of DW reflects the situation of no autocorrelation;

Value of adjusted $R^{2}$ of 0.603 conveyed that the independent variables used under the study;

Salary and benefits, career opportunities and work life balance explained 60.30 percent variation in retention intention. From the regression analysis it has been found that all independent variables explain the dependents variables.

Where

$$
Y=21.466+0.564 X_{1}+0.245 X_{2}+0.145 X_{3}+e
$$

$Y=$ dependent variable (retention intention)

$X_{1}=$ Salary and benefits

$X_{2}=$ career opportunity

$X 3=$ Work life Balance

Based on regression analysis considering beta coefficient it has found that salary and benefits is the most influencing factor of retention intention followed by, Career Opportunity, and Work Life balance are significant.

Ranking the Effects of Retention Variables on Retention Intention

Through considering the effect of value of beta coefficient of multiple regressions, independent variables are ranked on the basis of their effect on from highest to lowest effect on retention intention as follows:

Table 3

Ranking the Effects of Retention Variables on Retention Intention

\begin{tabular}{lcc}
\hline \multicolumn{1}{c}{ Variables } & Bata & Rank \\
\hline Salary and benefits & 0.564 & $\mathrm{I}$ \\
Career opportunity & 0.245 & $\mathrm{II}$ \\
Work life balance & 0.145 & $\mathrm{III}$ \\
\hline
\end{tabular}


The table 3 advocates that, salary and benefits explain the retention intention in highest extent and other variables; career opportunity, work life balance respectively explain the effect on retention intention from highest extent to the lowest besides the compensations.

\section{Conclusion}

Based on the above analysis, the study has drawn some meaningful conclusion having managerial implications in the field of human resource retention. It can be concluded that employee retention is a complex phenomenon that requires strategic orientation towards retention factors that covers salary and benefits, career opportunities, work life. It can also be concluded that all retention factors have positive and significant relation with retention intention. Although challenges are present in relation to management of all retention factors; compensation management is the most critical issues in Nepali insurance sector. In a nutshell, to retain the capable and competent employees a good management should not only focus on salary and benefits but equally give emphasis on career opportunities and work-life balance, and other motivational factors so that the performance level of the organization will be booming up.

\section{References}

Aswathappa, K. (2005). Human Resource and Personnel Management. New Delhi: Hill Publishing Company Limited.

Ali, N., and Baloch, Q.B. (2001) Prediction of Organizational Commitment and Turnover Intention of Medical Representative and Empirical Study of Pakistani Companies. Journal of Managerial Science, Vol. 3(2), pp. 263-275.

Cascio, W. F. (2006). Managing Human Resource: Productivity, Quality of Work life, Profits. New Delhi: Tata McGraw-Hill Publishing Company Limited.

DeCenzo, D. A., \& Robbins, S. P. (2005). Fundamentals of Human Resource. New Delhi: John Wiley and Sons Inc.

Graddick, M. N. (1998). Corporate Philosophies of Employee Development, Career Growth and Human Resources Strategies. The role of the human resources professional in employee development London.

Griffeth, R. W., \& Hom, P. W. (1995). The Employee Turnover Process. Research in Personnel and Human Resource Management, Vol. 13(24), pp. 245-293.

Gumbus, F.L., \& Johnson, C.R. (2003). Employee Friendly Initiatives at Futura. Leadership Survey, certification and a Training Matrix, and an Annual Performance and Personal Development Review, Vol. 54 (2), pp. 245-251

Heneman, H.G and schwab.D.P. (1985). Pay satisfaction its multidimensional nature and measurement Internal Journal of psychology, 20(24):129-141

Johnson, M. (2000). Winning the people war, talent and the battle for human capital. London: Licensing Agency

Jyothi, P., \& Venkatesh, N. D. (2006). Human Resource Management. New Delhi: Oxford University Press

Khadka, S. (2009). Foundations of Human Resource Management. Kathmandu: Pradhan Book House.

Journal of Business and Social Sciences (JBSS) 
Khuong M. N. \& Tien B .D.(2013). Factors Influencing Employee Loyalty Directly and Indirectly through Job Satisfaction: A Study of Banking Sector in Ho Chi Minh City. International Journal of Current Research and Academic Review, Vol. 1(4), pp. 81-95.

Phillips, J.J., \& Connell, A.O. (2003). Managing Employee Retention: A Strategic Accountability Approach, Butterworth-Heinemann. Elsevier, Chelsea.

Samuel, M.O, \& Chipunza, C. (2009). Employee Retention and Turnover: Using Motivational Variables as a Panacea. African Journal of Business, Vol.3(8), pp.410-415. 